\title{
Argumento e predicado em Tupinambá
}

\author{
Aryon Dall'Igna Rodrigues
}

1. O Tupinambá é uma língua indígena da família Tupí-Guaraní, falada em grande parte da costa atlântica do Brasil, a qual foi amplamente documentada nos séculos XVI e XVII, mas que foi deixando de ser falada, principalmente devido ao extermínio de sua população, num processo que praticamente se concluiu na primeira metade do século XVIII. As fontes documentais aqui utilizadas são indicadas abreviadamente após os exemplos e vão listadas no fim do artigo. Como a maioria das línguas, o Tupinambá tem duas classes lexicais principais, o nome e o verbo. Estas são identificáveis morfologicamente, pois os verbos podem receber prefixos pessoais marcadores de sujeito, o que não acontece com os nomes. Os prefixos pessoais marcadores de sujeito ocorrem nos verbos só quando estes são núcleos de predicados de orações principais, como em:

(1) ere-jú pe

(2suJ-vir INT) "você veio?" (Léry 1580:306)

(2) páa-júr

(sim 1suJ-vir) "sim, eu vim" (Léry 1580:306)

(3) aßá-Ø pe erima?é ikó Tár-a o-j-moján

(pessoa-ARG INT antigamente este mundo-ARG 3 SUJ-NCONT-fazer) "quem antigamente fez este mundo?" (Araujo 1618:36v)

O exemplo (3) mostra que os verbos transitivos têm mais um prefixo ( $i$-), situado entre o marcador de sujeito (o-) e o tema (moján "fazer"), o qual se refere ao objeto direto. A maioria dos demais recursos morfológicos do Tupinambá são comuns aos nomes e aos verbos. 
2. Nomes, verbos e posposições constituem nesta língua as três classes lexicais dotadas de flexão. Há nela um processo morfossintático com alta frequência de ocorrência que é comum a essas três classes e que consiste na marcação da dependência de um determinante (ou nome dependente) em relação ao núcleo de uma construção sintática, por meio de prefixos flexionais acrescentados ao núcleo. O determinante de um nome é o seu possuidor, o de um verbo intransitivo é o seu sujeito, o de um verbo transitivo é o seu objeto e o de uma posposição é o objeto desta. Os prefixos, além de estabelecer a relação de dependência (como o status constructus das línguas semíticas), assinalam a contiguidade ou a não contiguidade sintática do determinante. Cada marcador tem dois alomorfes cuja distribuição divide todos os nomes, verbos e posposições em duas classes morfológicas: classe I com ø-para contíguo e $i$-para não contíguo e classe II com $r$-para contíguo e $s$ - $\infty t$-para não contíguo. Os exemplos abaixo mostram o marcador de contiguidade (CONT) e o marcador de não contiguidade (NCONT) ocorrendo com nomes em função de argumento $(4,5,6,7)$, nomes em função de predicado $(8,9,10,11)$, verbos intransitivos $(12,13,14)$, verbos transitivos $(15,16,17,18)$ e posposições $(8$, $9,10,11,14)$ :

(4) marã pe né r-ér-a (como INT você CONT-nome-ARG)

"como é o nome de você?" (Léry 1580:306)

(5) marã pe pé r-oßájár-a r-ér-a (como INT vocês CONT-inimigo-ARG CONT-nome-ARG) "como é o nome dos inimigos de vocês?" (Léry 1580:318)

(6) marã pe s-ér-a (COmO INT NCONT-nome-ARG) "como é o nome dele?" (Léry 1580:324)

(7) wirá-Ø r-áß-a (pássaro-ARG CONT-pena-ARG) "a pena do pássaro" (Figueira 1687:71)

(8) kwesé ka?á-Ø r-upí o-watá-ßo Pedro r-opár-i (ontem mato-ARg CONT-por 3suJ-andar-GER Pedro CONT-perdido-CIRC)

"ontem Pedro se perdeu, andando pelo mato" (Figueira 1687:95) 
(9) kwesé ka1á-Ø r-upí Pedro o-watá-ßo s-opár-i

(ontem mato-ARG CONT-por Pedro 3sUJ-andar-GER NCONT perdido-CIRC)

"ontem, andando pelo mato, Pedro se perdeu" (Figueira 1687:95)

(10) kwesé né r-esé Pedro Ø-ma?ên wár-i

(ontem você conT-acerca Pedro conT-lembrança-CIRC)

"ontem Pedro se lembrou de você" (Figueira 1687:95)

(11) kwesé Pedro né r-esé i-ma?ẽnwár-i

(ontem Pedro você CONT-acerca NCONT-lembrança)

"ontem Pedro se lembrou de você" (Figueira 1687:95)

(12) né r-úr-eme a- Ø-juká umwán

(você CONT-vir-SUBJ 1sUJ-NCONT-matar já passado)

"quando você veio, eu já o tinha matado" (Anchieta 1595:21v)

(13) opukúßo táß-a r-én-i

(de comprido aldeia-ARG CONT-estar.sentado-CIRC)

"a aldeia esta assentada ao comprido" (Anchieta 1595:43)

(14) $\quad t$-ú $\beta$-a (...) Ø-Rekatwáß-a Ø-kotí s-én-i

(HUM-pai-ARg CONT-mão direita-ARG CONT-para o lado de NCONT-estar sentado-CIRC)

"ele esta sentado à mão direita do pai" (Araujo 1618:15)

(15) koromõ sjé r-epják-i

(logo eu CONT-ver-CIRC)

"logo me veem" (Anchieta 1595:39v)

(16) koromõ s-epják-i

(logo NCONT-ver-CIRC)

"logo o veem" (Anchieta 1595:39v)

(17) koromõ sjé né Ø-juká-w

(logo eu você CONT-matar-CIRC)

"logo eu te mato" (Anchieta 1595:39v)

(18) korí i-juká-w

(hoje futuro NCONT-matar-CIRC)

'hoje o matam' (Anchieta 1595:39v) 
O processo de marcação de dependência em Tupinambá opera com mais dois prefixos, que aqui são apenas mencionados, pois nada acrescentam ao tema desta comunicação. Um deles tem os alomorfes $m$ - $\infty \emptyset$ - para a classe I e $t-\infty \emptyset$ Ø- [perda da vogal inicial] para a classe II e assinala que não há determinante expresso sintaticamente, mas há uma relação de dependência com seres humanos em geral (molír < m-polír "colar usado pelas pessoas" moraséj < $m$-poraséj "dançar de gente", t-eté "corpo humano", t-eiké-áß "entrada de gente", $t$-oßaké "diante de gente"); o outro tem a mesma forma nas duas classes, $o-$, e indica que o determinante é idêntico ao sujeito da oração principal (o-polt́r "seu próprio colar", o-eté "seu próprio corpo").

3. Os nomes podem receber um conjunto de sufixos casuais. Há quatro tipos de caso locativo: locativo pontual (com o sufixo -pe $\sim$-ipe), locativo difuso (com o sufixo $-\beta o \sim-i \beta o$ ), locativo situacional (com o sufixo $-i$ ) e translativo (com o sufixo -amo -ramo); um caso vocativo não marcado (sufixo Ø) e um caso argumentativo (com o sufixo $-a \sim \emptyset$ ). Este último (antes chamado caso nominal ou nominativo) compreende todas as principais funções gramaticais, como as de sujeito de verbos intransitivos e transitivos, de objeto direto, de possuidor e de objeto de posposição. Os exemplos abaixo ilustram alguns desses casos:

(19) a-só ók-ipe

(1suJ-ir casa-LOCPT)

"vou para casa" (Figueira 1687:121)

(20) a-só ók-ißo

(1sUJ-ir casa-LOCDF)

"vou pelas casas" (Figueira 1687:7)

(21) isé t-úp-amo a-ikó ne

(eu NCONT-pai-TRANSL 1sUJ-estar INT)

"eu estarei como pai dele" (Figueira 1687:121)

(22) sjér-uß-Ø wé

(eu conT-pai-voc ó)

"ó meu pai!" (Figueira 1687:9)

(23) tapi?ír-a o-só ók-a Ø-kotí

(vaca-ARg 3SUJ-ir casa-ARG CONT-para o lado de)

"as vacas foram para a banda das casas" (Figueira 1687:124-125) 
(24) sjé r-úß-a t-oßajár-a ja-Ø-?ú

(eu CONT-pai-ARG HUM-adversário-ARG 3sUJ-NCONT-comer)

"os contrários comeram meu pai" (Anchieta 1595:36v)

(25) kwesé pajé-Ø maléasṫ̉ór-a Ø-sußán-i

(ontem pajé-ARG o.doente-ARG CONT-chupar ritualmente-CIRC)

"ontem o feiticeiro chupou ao enfermo" (Figueira 1687:96)

(26) aßá-Ø pe erimalé ikó Tár-a o-j-moján

(pessoa-ARG INT antigamente este mundo-ARG 3sUJ-NCONT-fazer)

"quem antigamente fez este mundo?" (Araujo 1618:36v)

(27) ma?é-ø pe erima?é o-j-mojáy ?ár-amo

(coisa-ARG INT antigamente 3sUJ-NCONT-fazer mundo-TRANSL)

"que coisa ele fez/transformou no mundo?"

(isto é, "de que ele fez o mundo?") (Araujo 1618:36v)

(28) i $\quad \dot{\hat{t}-} \emptyset r-u p t$

(terra-ARG CONT-por)

"por terra" (Anchieta 1595:43v)

(29) o-sí-Ø Ø-posé pitán-a $r$-ú( $(\beta)-i$

(3COR-mãe-ARG CONT-deitado.com criança ARG CONT-estar.deitadoCIRC)

"com sua mãe está deitada a criança" (Anchieta 1595:44)

4. Os nomes são ou possuíveis ou não possuíveis. Não possuíveis são os que designam elementos da natureza, aí incluídas as espécies animais, as plantas silvestres, isto é, não cultivadas, e as categorias físicas de seres humanos, assim como elementos do mundo sobrenatural; possuíveis são os que denominam partes de um todo, atributos e membros de um sistema de relações, bem como os artefatos humanos, aí incluídas as plantas cultivadas. Na expressão da posse o núcleo do sintagma possessivo recebe um prefixo relacional para dependente contíguo ou não contíguo, como acima nos exemplos (4), (5), (6), (7), (19), (22) e (24).

5. Os nomes possuíveis, sem os sufixos casuais, podem ser núcleos de predicados possessivos, os quais apresentam o mesmo comportamento gramatical que os predicados que têm por núcleos os verbos intransitivos, como se pode ver nos exemplos (30) a (33) abaixo (os exemplos dados sem referência a fonte estão construídos de modo a mostrar claramente o paralelismo 
das construções, mas mediante observância estrita dos paradigmas, regras e exemplos das fontes):

(30) orações independentes declarativas afirmativas:

(30a) ere-ín

(2suj-estar sentado)

"você está sentado" (Figueira 1687:58)

(30b) nér-ér

(você conT-nome)

"você tem nome"

(31) orações independentes declarativas negativas:

(31a) $\quad n(a)$ ere-ín-i

(não 2suJ-estar.sentado-NEG)

"você não está sentado"

(31b) na né r-ér-i

(não você CONT-nome-NEG)

"você não tem nome"

(32) orações dependentes afirmativas (ín "estar sentado" tem o alomorfe én nas orações dependentes):

(32a) né r-én-eme

(você conT-estar.sentado-suBJ)

"se/quando você estiver sentado"

(32b) né r-ér-eme

(você cont-nome-suBJ)

"se/quando você tiver nome"

(33) orações dependentes negativas:

(33a) né r-én-e?t́t-me

(você CONT-estar.sentado-NEG-SUBJ)

"se/quando você não estiver sentado"

(33b) nér-ér-ęṫ-me

(você CONT-nome-NEG-SUBJ)

'se/quando você não tiver nome'

6. Muitos nomes designam qualidades ou estados, tais como -ori $\beta$ "alegria", -asì "dor", -ún "pretume, escuridão", piray "vermelhidão", poráy "beleza", kane?õ "cansaço", ma?enwár "lembrança", etc. Como esses nomes são mais frequentemente usados como predicados, eles têm sido muitas vezes considerado adjetivos ou verbos descritivos. 
Entretanto, morfológica e sintaticamente eles não diferem dos nomes possuíveis, como foi indicado acima e como se vê também nos exemplos seguintes:

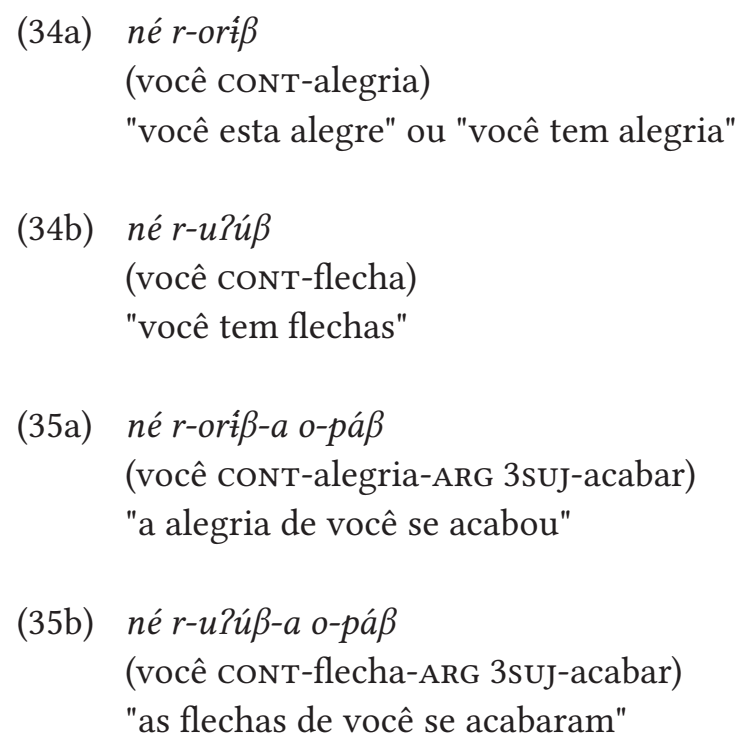

7. Não há sintagmas adjetivos em Tupinambá, mas a adjetivação é feita sistematicamente por composição. Há vários tipos de composição resultando em novos nomes (há também composição resultando em verbos), constituídos de nomes mais nomes e de nomes mais verbos. As composições de nomes mais nomes podem ser de dois tipos: (a) determinante + determinado, (b) determinado + determinante; as composições de nomes mais verbos são também do tipo (b), determinado + determinante. Os compostos do tipo (a) são compostos genitivos e os do tipo (b) são compostas descritivos. Em ambos os casos a composição é claramente distinguível da justaposição de palavras para constituir um sintagma, pois ela envolve processos morfofonêmicos específicos das junturas internas e ausentes das fronteiras de palavras, bem como só apresenta flexão relacional e de caso em suas fronteiras externas. Isto pode ser visto nos seguintes exemplos:

(36a) sjé r-u?ú $\beta$-urú-Ø

(eu cONT-flecha-recipiente-ARG)

"meu carcaz"

(36b) sjé $r$ - u?ú $\beta-a r$ - urú- $\emptyset$

(eu CONT-flecha-ARG CONT-recipiente-ARG)

"um recipiente para as minhas flechas" 
(37a) ja?wár-a?t́r-a (onça-filho-ARG)

"filhote de onça"

(37b) ja?wár-a r-a?t̂r-a

(onça-ARG CONT-filho-ARG)

"o filhote da onça"

(38a) ja?wár-ún-a

(onça-pretidão-ARG)

"onça preta"

(38b) ja?wár-a s-ún

(onça-ARG NCONT-pretidão)

"a onça é preta"

(39a) ja?wá-piním-a

(onça-pinta-ARG)

"onça pintada"

(39b) ja?wár-a Ø-piním-a

(onça-ARG CONT-pinta-ARG)

"as pintas da onça"

(39c) ja?wár-a i-piním

(onça-ARG NCONT-pinta)

"a onça tem pintas" ou "a onça é pintada"

Diante disso, faz todo sentido considerar os nomes de qualidades e estados como nomes possuíveis, que podem funcionar como núcleo de predicado tanta quanto os demais nomes possuíveis, e não como uma categoria à parte de verbos descritivos ou de verbos intransitivos inativos. Os predicados que os têm por núcleos são predicados intransitivos, como o são os que têm por núcleos os demais nomes possuíveis, como "nome", "flecha", etc. Um predicado intransitivo, nesta língua, pode ter por núcleo tanto um verbo intransitivo, quanto um nome possuível sem marcadores casuais.

8. Por outro lado, todos os verbos do Tupinambá, tanto intransitivos como transitivos, podem ser usados como argumentos, ou seja, como núcleos de sintagmas nominais. Nessa situação eles se comportam como nomes possuíveis e recebem marcadores de caso. Enquanto nomes possuíveis os intransitivos têm como determinante (dependente ou "possuidor") o seu sujeito, ao 
passo que o determinante dos transitivos é o seu objeto direto. Vejam-se os exemplos seguintes:

(40) a-j-potar né Ø-só-Ø

(1SUJ-NCONT-querer você CONT-ir-ARG)

"quero que vás" (Figueira 1687:156)

(41) sjé r-orî́ß né Ø-só-Ø r-esé

(eu CONT-alegria você CONT-ir-ARG CONT-por)

"folgo que vás",

lit. "eu estou alegre pela ida de você" (Anchieta 1595:27)

(42) sjé r-orít-katú né r-úr-a Ø-rí

(eu-CONT-alegria-bondade você CONT-vir-ARG CONT-por)

"eu me alegro muito pela vinda de você

(ou: por você ter vindo, ou: porque você veio)" (Léry 1580:316)

(43) né r-úr-a sjé Ø-mo-orî́ $\beta$

(você CONT-vir-ARG eu CONT-CAUS-alegria)

"a vinda de você me alegrou"

(44) sjé Ø-ma१enwár né r-úr-a r-esé

(eu CONT-lembrança você CONT-vir-ARG CONT-por)

"bem me lembro de vossa vinda"

(lit. "eu tenho lembrança da vinda de você") (Figueira 1687:157/158)

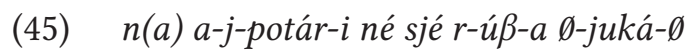

(não 1sUJ-NCONT-querer-NEG você eu CONT-pai-ARG CONT-matar-ARG)

"não quero que tu mates a meu pai"

(lit. "não o quero de você de mim pai o matar", isto é, "não quero a sua ação de matar o meu pai") (Figueira 1687:156)

(46) ma?é-Ø amõ né Ø-kér-ipe ere-s-epják

(coisa/animal-ARG algum você CONT-dormir-LOC 2sUJ-NCONT-ver) "você viu alguma coisa no seu sonho (lit.: no dormir de você)"

9. Há, portanto, o emprego de nomes como predicados e o emprego de verbos como argumentos, e o processo morfológico em ambos os casos é a marcação de caso: com marcador casual, tanto nomes quanto verbos funcionam como argumentos; sem marcador casual, uns e outros funcionam como 
predicados. Embora o caso locativo pontual ocorra também com argumentos de base verbal, o caso mais geral para a marcação de argumentos é o que chamamos de caso argumental, comum a todas as principais funções argumentais: sujeito de verbo intransitivo, sujeito de verbo transitivo, objeto de verbo transitivo, possuidor, objeto de posposição.

O Tupinambá é, pois, uma língua cuja organização sintática repousa diretamente na distinção, por meio da marcação de caso, entre argumento e predicado:

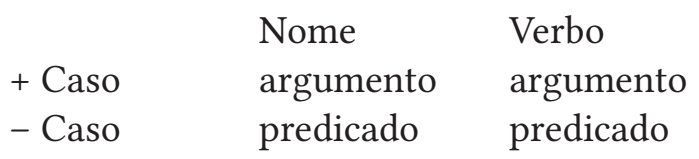

$\begin{array}{ll}\text { Abreviaturas usadas } \\ \text { ARG } & \text { sufixo do caso argumentativo } \\ \text { CIRC } & \text { sufixo do modo circunstancial } \\ \text { CONT } & \text { prefixo indicador de determinante contiguo } \\ \text { GER } & \begin{array}{l}\text { sufixo do gerúndio } \\ \text { (pred. de oração com o mesmo sujeito que a principal) }\end{array} \\ & \text { prefixo indicador de determinante humano } \\ \text { HUM } & \text { partícula interrogativa } \\ \text { INT } & \text { sufixo do caso locativo difuso } \\ \text { LOCDF } & \text { sufixo do caso locativo pontual } \\ \text { LOCPT } & \text { prefixo indicador de determinante não-contíguo } \\ \text { NCONT } & \text { sufixo marcador de negação } \\ \text { NEG } & \text { prefixo marcador de objeto direto } \\ \text { OBJ } & \text { sufixo do modo subjuntivo } \\ \text { SUBJ } & \text { prefixo marcador de sujeito } \\ \text { SUJ } & \text { sufixo do caso translativo } \\ \text { TRANSL } & \text { (também chamado caso predicativo) }\end{array}$

\section{Referências}

Anchieta, Joseph de (1595): Arte de grammatica da lingua mais usada na Costa do Brasil. Coimbra: Antonio de Mariz. (Eds. facsimilares: Leipzig: Teubner, 1876; Rio de Janeiro: Biblioteca Nacional, 1933; São Paulo: Ed. Anchieta, 1946; Salvador: Univ. Fed. da Bahia, 1980 e 1981; São Paulo: Eds. Loyola, 1990.)

Araujo, Antonio de (1618): Catecismo na lingoa brasilica. Lisboa: Pedro Crasbeeck. (Ed. facsimilar: Rio de Janeiro: PUC, 1952.)

Figueira, Luis (1687): Arte de grammatica da lingua brasilica. (Segunda edição). Lisboa: Miguel Deslandes. (Ed. facsimilar: Leipzig: Teubner, 1878.)

Léry, Jean de (1580): Histoire d'un voyage faict en la Terre du Bresil, autrement dite Amerique. 2a. ed. Genebra. (Ed. facsimilar: Genebra: Droz, 1975.) 